\title{
Easing transition and promoting a positive student experience within an international partnership scheme for British and Chinese teachers
}

Article

Accepted Version

$\mathrm{Li}, \mathrm{D}$. (2012) Easing transition and promoting a positive student experience within an international partnership scheme for British and Chinese teachers. Journal of Research in International Education, 11 (1). pp. 32-49. ISSN 1741-2943 doi: https://doi.org/10.1177/1475240911434338 Available at https://centaur.reading.ac.uk/25972/

It is advisable to refer to the publisher's version if you intend to cite from the work. See Guidance on citing.

To link to this article DOI: http://dx.doi.org/10.1177/1475240911434338

Publisher: Sage

All outputs in CentAUR are protected by Intellectual Property Rights law, including copyright law. Copyright and IPR is retained by the creators or other copyright holders. Terms and conditions for use of this material are defined in the End User Agreement. 


\section{CentAUR}

Central Archive at the University of Reading

Reading's research outputs online 


\title{
Easing transition and promoting a positive student experience within an international partnership scheme for British and Chinese teachers
}

\author{
Daguo Li
}

National Centre for Language and Literacy, The University of Reading

\begin{abstract}
This article investigates the needs and challenges of a group of Chinese secondary school teachers in their transition to postgraduate studies in the UK in the context of a BritishChinese partnership. The strategies and efforts of the host institution, local community and the Chinese students themselves to help ease the transition and promote a positive student experience are discussed. The article highlights the sociological processes of international postgraduate student transition and contributes to our understanding of issues of student support pertinent to international partnership arrangements.
\end{abstract}

Keywords: transition, postgraduate students, Chinese students, student support, international partnership

\section{Introduction}

In our increasingly globalised world (Giddens, 1991) and network society (Castells, 1997), the flow of people across national borders is becoming more commonplace. International education and student mobility are part of this trend. Large numbers of students pursue overseas studies, both in Western countries such as the US, UK, Australia, and Canada, and East and South East Asian countries such as China, Japan, Singapore and Malaysia. In recent years, an increasing number of international students have been able to take advantage of international partnership programmes where host higher education institutions (universities) work in collaboration with an overseas counterpart to offer both undergraduate and postgraduate degree programmes in the host country. 
Given the importance of international students for both higher education and the wider economy, much effort has been made to understand their experiences and to improve the quality of support they experience UKCOSA, 2004, 2007; Commonwealth of Australia, 2007; Australian Education International, 2010). In the UK, the Chinese constitute the largest group of international students (British Council, 2008) and, as such, have received much attention (e.g. Coverdale-Jones and Rastall, 2006; Edwards and An, 2006; Edwards, An and $\mathrm{Li}, 2007)$. The present study looks at the transition of a sub-group of the Chinese international student population - postgraduate students. More specifically it focuses on the stages of their transition within a sociological framework and the institutional strategies and societal efforts that help to ease their transition.

\section{Conceptual framework}

The work of van Gennep (1960) provides a useful theoretical framework for understanding the transition experience of international students. Transition, or shift from membership of one group or community to another, is pervasive in human groups and societies. According to van Gennep (1960: 2-3), the life of an individual in any society consists of 'a series of passages from one age to another and from one occupation to another'. Such movements are accompanied by special acts, ceremonial patterns or rites. Because of the importance of transitions in the social world, van Gennep proposes a conceptual framework to account for these rites of passage. He distinguishes three types or categories in his conceptual framework: preliminal rites or rites of separation (i.e. separation from a previous group or world), liminal rites or rites of transition (i.e. transition to membership of a new group or world), and postliminal rites or rites of incorporation (i.e. incorporation into the new group or world). He argues that the significance and elaboration of the three types vary with social groups and specific situations. For instance, rites of separation have prominence in funeral ceremonies whilst rites of incorporation are significant in marriages; transition rites are important in pregnancy but may be less so in adoption. He also recognizes the complex nature of social processes and activities which these categories aim to represent and the possibility of different levels of analysis. In his view, the usefulness of the framework lies in its 
heuristic value rather than the rigidity of a classification scheme. The framework has been used to explain transition processes in education. For example, Tinto (1988) analysed in great detail the transitional stages of first year undergraduate students in terms of separation (from the local high school and family), transition (the process of acquiring norms and behaviour characteristic of membership of a new college community), and incorporation (integration into the community of the college).

Whilst the first year of undergraduate study is widely regarded as a typical context for discussions of transition (McInnis, 2001; Trotter and Roberts, 2006; Moss, Pittaway and McCarthy, n.d.), transition is also a feature of other educational contexts and discourses. For example, Lucey and Reay (2000) and Anderson, Jacobs, Schramm and Splittgerber (2000) discuss the transition from primary to secondary school, and Graham (1997) the transition within secondary education from GCSE (General Certificate of Secondary Education) to A-Levels (Advanced-Levels) in the educational system of England. There is also an emerging interest in the transitional experiences of international students in Western universities both at the undergraduate level (e.g. Ramsay, Jones and Barker, 2007; Gu, Schweisfurth and Day, 2010), and at the postgraduate level (e.g. Lewthwaite, 1996; Hellstén, 2002; Jepson, Turner and Calway, 2002; Guilfoyle, 2006; Singh and Armstrong, 2006). Lewthwaite (1996) examines the transitional experiences of 12 East Asian postgraduate students in New Zealand. Based on students' self-reports he identifies, among other issues, the stress associated with producing written or oral work in English, tension between academic work and socialization, and the relationship between student satisfaction and regular contact with members of the local communities (e.g. their academic supervisors and homestay families). Gu et al. (2010) study the experiences of first-year international undergraduate students at four UK universities. They highlight the complex transitional experiences of international students, involving both maturational development and intercultural adaptation.

The majority of these studies on the transition experiences of international students tend to adopt a more psychological perspective. There is very little explicit discussion of the transition processes in these contexts within a sociological framework of the kind 
proposed by van Gennep (1960). The case study upon which this article is based aims to fill this gap by examining the transition processes of a group of Chinese secondary teachers on a postgraduate programme at a UK university within a partnership arrangement, and the strategies institutions and other social groups adopt to facilitate this transition. Specifically, it seeks to answer the following questions:

1. What are the needs and challenges of Chinese students in their transition to postgraduate study in the UK?

2. What strategies do the host institution and other social groups deploy to ease this transition and promote integration and a positive student experience?

\section{Methodology}

The present study adopted a case study design, aiming to present rich data and an indepth analysis of the transitional experience of a cohort of 11 Chinese students on an MA programme (hereinafter referred to as the Chinese cohort) at a university in southern England (hereinafter referred to as the University) during the academic year 2006-7 (beginning September 2006). The Chinese cohort came to study as a partnership arrangement between the University and a local education authority in China. They were all secondary teachers of English before they were enrolled and all had to fulfil the English language requirement, which was an average IELTS score of 7.0. There were 3 men and 8 women, and their ages ranged from late 20 s to 30 s.

One distinctive advantage of the case study strategy is that it can encompass multiple sources of evidence or methods of data collection. The challenge, though, is where to draw boundaries in terms of the phenomenon and the context of a case, i.e. in making decisions about where to begin and where to end, or what to include and what to exclude (Yin, 2003a, 2003b; Stark and Torrance, 2005). In undertaking this study it was decided that, in addition to the views and voices of the Chinese cohort, views should also be sought of other key players in the Chinese students' experience, including academic staff and support staff involved with them at the School of Education (the School for short) and of in-sessional language support tutors at the University. In the course of data 
collection, it soon emerged that a local volunteer group (LVG) was involved in supporting the students both socially and culturally and it was decided that additional views needed to be sought from LVG representatives. To ensure anonymity of the respondents, pseudonyms will be adopted for all the respondents and used consistently throughout this article.

Data were collected at several stages. A focus group discussion was conducted with the Chinese cohort in the Spring Term 2007. Individual interviews with representatives of the LVG were carried out towards the end of the Spring Term, while individual interviews with academics and support staff, and the collection of essay grades, took place towards the end of the Summer Term 2007. Individual interviews with the students were conducted in September 2007, when the students were completing their dissertations. The students' dissertation results were obtained in November 2007, after confirmation by external examiners and the relevant examination board of the University.

Such a design allowed for triangulation (by gathering data from different sources) and respondent validation (e.g. issues emerging from early focus group discussions could be checked or followed up at a later stage of individual interviews with the students). It also enabled the generation of rich data and in-depth analysis (Stark and Torrance, 2005) of the processes of the students' transition embedded in its complex social and cultural context (Yin, 2003a, 2003b), thus complementing previous snapshot surveys towards the end of an academic year typical of large scale surveys of international students (e.g. UKCOSA, 2004). It was hoped the design would also go some way to addressing the concerns expressed by Leonard, Pelletier and Morley (2003) about the lack of data on achievement and outcomes in the vast majority of research on international students.

\section{Data analysis and results}

All the interview data were transcribed and prepared for analysis with ATLAS.ti 5.0, a sophisticated specialist software program for the analysis of qualitative data. Whilst each software package has its own strengths and weaknesses (Weitzman and Miles, 1994; Lewins and Silver, 2009), ATLAS.ti 5.0 was deemed suitable for the purpose of the 
present project. It allowed the systematic coding of the data with the possibility of different analytical strategies and facilitated identification of the common themes. Its seemingly inconvenient lack of hierarchical structure also enabled the researcher to exercise more power in data interpretation and organisation and resolve, to some extent, issues of compatibility of technology (based on logical, objective and quantifiable principles) and qualitative data analysis (based on subjective, interpretive, and meaning seeking philosophies) (Roberts and Wilson, 2002). The results are presented below in relation to the research questions in terms of the needs and challenges facing the Chinese cohort, and the strategies and efforts of the host institution and other social groups to ease the student transition. These will be discussed within the conceptual framework of van Gennep (1960): separation, transition and incorporation, with a focus on transition, which has particular prominence in the Chinese cohort's experience.

\section{Needs and challenges}

It emerged from the present study that the main needs and challenges arising out of the transition to postgraduate study in a new world - the new educational, social and cultural context of the UK - could be grouped as follows:

- psychological: feelings of emptiness and potential isolation away from familiar social and professional networks,

- linguistic-academic: the need and challenge of acquiring the necessary linguistic and academic competencies in their transition to the new academic communities, and

- sociocultural: the need for extended social and cultural experiences, often beyond their immediate academic environment.

\section{Separation}

Pursuing postgraduate study overseas naturally involves a stage of separation. Despite the scale and frequency of people flow in our increasingly globalised world, departure for study overseas for the Chinese today still seems to exhibit features of the long-standing festive rites of separation marking the departure and travel away associated with the ancient officialdom (see example in van Gennep, 1960: 36). These rites include gift- 
giving from friends and relatives (in some cases substantial amounts of money), farewell banquets, best wishes, and accompaniment to "the road" (nowadays stations and airports). However, it could also be painful for members of the Chinese cohort to suspend membership of their former groups, such as family and professional colleagues, even temporarily. As they were all mature students, several married with a young child left behind, initial feelings of loneliness and emptiness could be overwhelming:

When we first arrived, we all had this type of feeling, that is, as soon as we put our luggage down and closed the bedroom door, many female students in our group wanted to cry. Even we three men [felt like doing the same]. I was asking myself, 'Oh, how am I to survive this long year ahead?' I couldn't sleep even after midnight, perhaps also because of the jet lag. That sort of anxiety. (Feng, Interview)

The younger unmarried ones among the group seemed to have mixed experiences at this stage. For one of the youngest students, Hongmei, from the very start it was a case of whether to stay on or withdraw from the course. She had felt considerable pressure from her father to study in the UK. Yet before she came, she was extremely dependent on her parents in most aspects of her life. For her, as may be the case for many of the 'only child' in present day China, leaving home to study overseas was perhaps no less than a baby being suddenly cut off from its mother's milk. When she first arrived, she could not bear the idea of being suddenly left on her own in a foreign land. She cried every time she phoned her father. She simply wanted to return to China immediately.

In contrast, Jing seemed to have a sense of liberation and thoroughly embrace the opportunities for learning and experiencing another culture afforded by her overseas study:

I have always had a nostalgic feeling about the UK. I seemed to love English literature, and then I chose to study the English language and I felt I liked the language very much, because I felt the language is beautiful... Here I am now, in the UK. I wanted to find out how the British [speak English]. Oh, they speak English like that, and their society, history and culture. And I feel I like every 
aspect of the UK, everything, in addition to literature, everything. (Jing, Interview)

Also significant was the change of membership from a professional group, i.e. as an experienced and competent secondary school teacher in China, to a student and a novice researcher in a different linguistic, social and cultural environment in the UK. This membership change brought with it great challenges which became apparent at the stage of transition.

\section{Transition}

Because of the short duration of the Masters programme in the UK (normally one year) it can be argued that the entire year is essentially a period of transition. Academically, students need to go through a process of socialization into the new 'community of practice' (Swales, 2003: 203) or 'discourse community' (Berkenkotter, Huckin and Ackerman, 1991: 192). Membership of the discourse community, including mastering its 'academic literacy' or 'academic communicative competence' (Berkenkotter et al.,1991: 211) - ways of speaking, reading, and writing appropriate to the particular academic community - was crucial for the successful transition by the Chinese Cohort. This academic literacy is often markedly different from the language to which people are accustomed at university or as a teacher in a school setting. Berkenkotter et al. (1991) document the learning process of a new PhD student called Nate in an American university, who was a native speaker of English and skilled writer, with substantial prior experience in both creative writing and teaching writing to first-year undergraduate students. He nevertheless needed explicit training in the conventions of academic writing (e.g. social science expository writing), the mastering of which is often considered to be a formidable task. The training included instruction on the basic conventional structure of research report writing, such as introduction, methods, results, and discussion. These aspects of academic writing pose challenges even for native speakers.

The task facing the Chinese cohort was equally, if not more, formidable, given that they did not have a background of research or experience in extended writing in English. The following excerpts from the data show the extent of the challenges facing them: 
At the start I didn't know how to write a 5000 word essay - how to write an essay, how to write an introduction, and how to write a conclusion - I seemed to have little idea. (Jing, Interview)

One [challenge] was my linguistic competence. ... we were suddenly asked to express our ideas [in English], which should be critical as well. That was a real challenge and we needed to adapt to this new approach to learning. ... In terms of assignments, [initially] I didn't know how to write them and how to develop a paper. No idea, no feel for it at all. ... People here were talking about plagiarism and [warned] that the penalty was severe. On the one hand, I was afraid of not using sufficient quotation, but on the other hand, I feared that if quotations were not used appropriately, they were branded as plagiarism. ... Another problem was after the quotation how I should develop my critical idea, that is, although I knew it was expected of us, I had little idea as to how to develop it. (Yuhua, Interview)

Lack of confidence and the feeling of anxiety in relation to academic work seemed to characterise many of the students in the Chinese cohort, particularly in the early stages of their programme. Data from both the focus group and the interviews with the students illustrate these concerns:

I didn't seem to be myself after I came here ... Sometimes I felt very anxious. I wanted to finish [reading] the book. Sometimes I could not understand [what I had read]. Sometimes there were different arguments. One book argued this way while another argued that way. After reading I was totally confused. After finishing a chapter, I couldn't remember what it was about. In such cases, I just felt very annoyed and anxiety started to grow. (Hui, Focus group)

Like last term, the writing of assignments, ... although I didn't care too much about the results and I believed I could pass, during the process, I felt very tense, because I was afraid that I could not complete [the assignments] in time, and I am the sort of person who cannot write anything if I'm feeling tense. So I gave up my plan for travelling to Scotland [over Easter], although I had booked it and [Dr 
Zhang - Haiyan's Personal Tutor] had also tried to persuade me to go. (Haiyan, Interview)

One of them (Xiaoli) believed, however, that such a level of pressure and anxiety was unhealthy and unnecessary, given that most students could succeed with sufficient effort, as in the case of Haiyan above. She recommended therefore that measures should be taken by the University to ensure that future cohorts would not be subject to the same level of pressure and anxiety as they had experienced.

Studying overseas for the Chinese cohort did not simply mean reading papers and writing assignments. They also wanted to have some social life outside of the 'Ivory Tower'. Through socialisation into, or membership of, the wider local community, they hoped to have the additional benefits of improved linguistic knowledge and cultural understanding.

\section{Strategies and efforts to facilitate transition}

Based on its understanding of the experiences of past international students and these emerging needs and challenges, the University adopted three main strategies to help the Chinese cohort to socialize into the academic community and have a positive student experience:

- Implementing a new support structure to strengthen international student support;

- Providing specific support for study skills and language;

- Adopting an encouraging attitude and being responsive to emergent student needs.

These strategies were complemented by efforts of the wider community to enrich the students' social and cultural experiences and by the efforts made by members of the Chinese cohort themselves to support each other. Each of these will now be discussed in turn in some detail.

\section{Implementing a new support structure}

One strategy adopted by the University was to implement a new support structure to facilitate socialisation for international students, particularly the Chinese cohort, into the 
academic community. This new support structure had two key features. First, a newly appointed International Programmes Coordinator, Emma, was responsible for organising an enrichment programme for international students across the different programmes at the School. Second, additional support was provided by a Chinese member of staff, Dr Zhang - as the Chinese Cohort would prefer to call him - who worked closely with Emma. (As with all other names used in this article, Emma is a pseudonym). Both Emma and Dr Zhang had the full support of John, the School's Director of Teaching and Learning. This new support structure was designed to exploit the cultural insights from both the British and Chinese members of staff and ensure that the needs and challenges of the Chinese cohort, as discussed earlier, were anticipated or responded to.

The purpose of the enrichment programme, designed and implemented by Emma, was to complement University central provision (e.g. Accommodation, Counselling, Careers) and strengthen the pastoral, cultural, social, and academic support, particularly for the Chinese cohort, over the academic year. It included practical visits, workshops and presentations covering a wide range of topics such as local cultural orientation, academic induction, social events for students and staff, and dissertation workshops. It was often based on recognition of support needs at important junctures of international student transition. One good example of this was the recognition of the need for adequate support in the run up to the Christmas holiday, when international students were likely to have the first serious taste of academic pressure, anxiety, loneliness and isolation, as summarised by John:

Partly to do with literally physically where we are in the year - it's winter, it's cold. With Christmas coming up, it's a big gap. I think with many international students, this is a problematic period. The University is semi-closed. ... We know that about week 7 or 8 , when everyone has chosen their topics, discussed with their tutors and beginning to realize just how much they have to do... I think we try both formally and informally, very hard at that point to say... the term's finished but we don't. If you need to come to talk to us, come to see us, come to discuss your essay, send me an email, you can do that. 
The enrichment programme created valuable additional opportunities for interaction with members of the wider academic community (e.g. tutors and other international students). For example, dissertation workshops were generally considered valuable by the Chinese cohort: 'Very useful. You can't just shut yourself in your bedroom and work in isolation. You need to talk to others and know how they are progressing' (Jing, Interview). In the earlier stages of their transition, the new support structure helped the Chinese Cohort to develop a sense of belonging (i.e. at the School level), which seemed in sharp contrast to a feeling of being lost in the wider university community. It also helped with retention (i.e. preventing withdrawal from the university) in the case of one student, which will be discussed in more detail later.

\section{Providing specific support for study skills and language}

Another strategy adopted by the School included measures to induct the Chinese cohort to the appropriate levels of academic literacy, particularly reading and writing skills and linguistic terminology, which were identified as facilitative of their transition to postgraduate study and important for their academic success. One of the measures was the introduction of a new credit-bearing module, English Language and Study Skills, at Master's level, and another was targeted in-sessional language support for their writing over two terms. These measures were designed to equip the Chinese cohort for subsequent study and research and to help them adapt to the academic writing conventions in the UK and cope with the demands of writing their assignments and dissertation.

The English Language and Study Skills module was dubbed 'bootstrapping' by Colin, Academic Tutor and Module Leader:

Well, it was specifically geared towards the Chinese students ... and it was regarded as a way... of bootstrapping .... of giving them the tools and methods and mechanisms to succeed better in their second term than in their first, and by giving them the terminology, and the practice with their English language, basic research skills, academic skills, the kinds of things that seem to be lacking in a lot of the international students, and also in a number of British students ... 
The Chinese cohort had found particularly useful the advice given by the Study Advisor at one of the module sessions, which encouraged selective reading: 'Think more, read less' rather than trying to read from cover to cover - an approach which the students had been more accustomed to back in China. Other practical sessions such as research methods workshops were also perceived as useful by the Chinese cohort because of their hands-on nature. Interestingly, they expressed the wish to have the module extended to two terms so that they could have more practice. On the other hand, another workshop on literature searches in the library, due to the insufficient opportunities for hands-on experience, was considered to be less useful.

The writing course was a special arrangement - the result of some negotiation between the School and the University's in-sessional language support team. It was offered over the first two terms, with a combination of both group teaching and individual tutorials. The course is normally offered by the University to science PhD students to help with their writing of science reports. The Chinese cohort were Education students so the tutor needed to adapt the course to make it more relevant to their needs. The in-sessional language tutor for writing, Alice, explained the rationale and benefits of the course as such:

Well, I think it makes them aware, more than anything else, of what good academic writing in English is ... hopefully it teaches them to observe the characteristics of good writing when they read, so indirectly I hope it helps them with their reading and by being better readers, that's how you become a better writer... These classes are not a quick fix at all, but ... it's raising their consciousness about writing, being aware of processes, and what standards are in British universities. And hopefully not to frighten them - 'Oh, I can never achieve that standard!' - because I also try to convey to them that ... English is not their first language and we are tolerant of that.

The tailor-made writing course was felt to be useful and immediately relevant to their first term's assignments by all the members of the Chinese cohort. It helped them, for 
example, to understand the need to approach writing in a more structured manner (e.g. how to start off with an outline, how to approach different parts of the essay, and how to develop an essay). It also helped them to better understand how to follow expected conventions of academic writing, such as referencing, paraphrasing and quoting and therefore avoid pitfalls such as plagiarism. Issues such as plagiarism are often a concern among academics teaching or supervising postgraduate students and the causes are complex and a matter for debate (Handa and Power, 2005; Leask, 2006; Macdonald and Carroll, 2006; Edwards et al., 2007). Although warnings of plagiarism are normally inserted in the postgraduate handbooks and students know the potential punishment, they may not know how to avoid it in practice without awareness raising and scaffolding (e.g. contextualisation, exemplification and practice) and some internalisation (see, e.g., Emerson and Rees, 2005; McGowan, 2005). It was clear from the above discussion that the writing course helped to raise awareness of several important issues relevant to the Chinese cohort (e.g. writing conventions and plagiarism) at an earlier stage of their programme and provided some necessary scaffolding, which were perceived to be useful by the students when they embarked on their first term's assignments.

\section{Adopting an encouraging attitude and being responsive to emergent student needs}

As discussed earlier, lack of confidence or anxiety in relation to academic work seemed to characterise many in the Chinese cohort. Both the course and in-sessional language support tutors recognised this problem, and the strategy they adopted was to offer much ongoing encouragement and reassurance and timely feedback in their academic work and language:

... with international students who have never been in a British university before, I think they just ... need more reassurance, you know, they're lacking in confidence. That's why I think you know it's so important to give them some kind of reply immediately, even it's only to say, 'Look, I'm too busy to look at your draft now, and I'll see you, I'll contact you tomorrow or the day after'. (Colin, Course Tutor, Interview)

... what they needed to do is to be assured, to have somebody to talk to them that 
they could trust and they had confidence in, who was qualified in the field that could say 'Yes, that was right.' ... I felt very much they needed a sympathetic approach, not to feel that they would be criticised all the time, but to build on the strengths rather than looking at the weaknesses. (Mandy, In-sessional language support tutor, Interview)

Such encouragement and timely feedback on their work in progress was very motivating for the Chinese cohort and helped them to build confidence:

Every time the tutor gives you the most satisfactory answer in the fastest way, it is very encouraging. So you won't feel your question is ignored. (Yuhua, Interview)

After the second term, the tutor noticed my progress and his comments were very encouraging. I felt I had made progress. ... Tutors' feedback and encouragement were very important. (Haiyan, Interview)

On the other hand, perceived lack of feedback or timely feedback could lead to anxiety and dissatisfaction among the students, as was the case with one tutor during the final stage of two students' dissertation supervision:

During the process [of my dissertation writing], I felt a slight lack of guidance. If you solely rely on your own efforts - as the dissertation is the final product of your one-year study - something seems missing... [I knew] my [dissertation] supervisor was extremely busy [over the summer], so I did not get timely feedback and I felt a bit disappointed. (Haiyan, Interview)

However, this could be one area where student and tutor expectations differ. The students seemed to expect more guidance and supervision and sometimes even direct feedback on whether something was right or wrong, as the following interview data indicates:

To a certain extent, I would expect my professor at least to tell me whether my work was right or wrong, good or bad, but the professor never said so, he only said ok, ok. So I felt very unsure about it. (Hualing, Interview) 
However, the tutors believed that the UK approach is really to encourage student independence with appropriate guidance or scaffolding. In fact one tutor, Colin, emphasised that one of the main criteria for a distinction grade, as standardised across all tutors, was students' demonstration of more independent work and less reliance on the tutor for input. Clearly, there is a gap between student and tutor expectations of both the level and form of academic support.

These support strategies were both proactive (based on anticipated student needs) and reactive (in response to emergent student needs), representing the School's recognition of the necessity for a more systematic approach to support for student transition, which required more intensive support upfront, as summarised by John:

The way that my colleagues ... have organized the MA means that there was a lot of support at the beginning, to help [the students] understand exactly what was needed, and I think that made a big difference. In other words, we anticipated various needs, so by Christmas, a lot of those needs had been addressed. ... I think by having the international program [The Enrichment Programme], with a very clearly identified person who is not an academic member of staff and not involved in assessing them, but supporting them... I hope and believe, they can go to that person, and say what about this, what about that. And finally of course, they have Dr Zhang ... who understands them, their needs, so we're in a very fortunate position by having, first of all Emma, and then Dr Zhang, to meet their needs.

The above strategies adopted by the School to actively support the needs and mitigate the challenges of the Chinese cohort seemed to facilitate the process of transition in the academic context. However, membership of the academic community was not the only aspiration of the Chinese cohort. They also had a strong desire for opportunities of social interaction with local communities outside the 'Ivory Tower' to broaden their experience, particularly with a view to advancing their language and cultural understanding. It is to discussion of this aspect of their transition that we now turn. 


\section{Facilitating broader socialisation}

As the Chinese cohort did not have many taught sessions, as is the case for most postgraduate programmes in the UK, they spent most of their time doing independent study, which could create a feeling of isolation. In addition, the fact that they came as a group on the same programme meant that opportunities for social interaction in English and cultural experience outside the group could be restricted. This lack of opportunity for socialisation was sometimes perceived by outsiders as a lack of ongoing support within the University:

When the new students come at the beginning of the Autumn Term, there is a big welcome: 'You are welcome! We are so happy that you have come.' That's it, finished, and nothing else happens. Because the [International Office] just wants to recruit more students for the next year, they forget about where they would go. (Richard, representative of LVG)

Such a stereotypical image of university support for international student transition is, of course, based on anecdotal observations by people outside of the system of support offered by the University. But evidence from surveys of international students does point to a feeling of isolation and a lack of social interaction with British students and local people (e.g. UKCOSA 2004). This was also the case with the Chinese cohort, who felt that the university environment did not sufficiently satisfy all their socialisation needs. For instance, the social events organised by the School were perceived as helpful but not regular or intensive enough to make an impact. Students had to look elsewhere for such opportunities. This was where local volunteer groups such as the LVG came in.

The LVG, a predominantly Christian group, had been well known locally for the care and support they had been offering to international students outside the academic context. After being approached and invited by the LVG, the Chinese cohort started to participate in its activities which included regular social gatherings, short one-day excursions over weekends during term time, and longer tours during university holidays. Some of these activities focused on cultural themes (e.g. International Food Night, Bonfire Night, and a Barn Dance). They also arranged for host family placement for Christmas. The 
participants in these events included the organisers from the local community and international students from different continents and faiths. According to both the Chinese cohort and the representatives of the LVG, the Chinese cohort often formed the majority at such events.

The benefits of this participation for the Chinese Cohort were manifold. All of them agreed on the linguistic and cultural gains; for example, the opportunities for social interaction with the local people and other international students to improve their English language skills, broaden their vision, and deepen their cultural understanding. They welcomed the practical and financial benefits; for example, the low cost one-day excursions and the longer trips to Scotland and Wales, which had saved them not only money but also time for organisation. They felt these activities helped to break isolation and provided opportunities for recreation and relaxation from the pressure of study, as Jing and Hui commented below:

Otherwise I would have felt very lonely - it seemed there was Bible Study every week so there was one more place to go - otherwise I would just be staying in my room every day. Some British people invited us to their homes to make cakes or have afternoon tea, things like that, and we also played croquet together. These offered us the opportunities to experience some typical stuff in the UK. Nice, really nice! (Jing, Interview)

... it could relieve the pressure of study, particularly at the start of the course, when we had difficulties. Since when you came across difficulties, you wanted to carry on studying in your room, but you just couldn't concentrate. Then after participating in those activities, you could work more efficiently. ... So it was quite helpful. (Hui, Interview)

They commended the organisers for their friendliness, care, warmth, and devotion to the cause of helping international students. Some of the members of the Chinese cohort were so moved by what the LVG had done for them that they started to think seriously about the Christian faith professed by the majority of the organisers. Undoubtedly, efforts of the 
LVG provided opportunities for membership of the local community, which would otherwise have been unavailable. Intensive and in-depth socialisation with members of the LVG not only enriched the cultural experience of the Chinese cohort and facilitated their transition but also seemed to have had a deep influence on them in terms of their cultural values and beliefs (Li, 2011).

\section{Offering mutual support and exploiting group dynamics in student transition}

One theme that emerged from the data pointed both to the significance of the Chinese cohort and to what could be called group dynamics in the context of support for transition within a partnership scheme. Although some academics and support staff did not always see the Chinese cohort as a 'group', the resources mobilised by the School seemed only possible when a significant number of Chinese students joined the programme. As such, the Chinese cohort, alongside other international students, was able to benefit from more targeted and enhanced support.

It also seems that, in the absence of family and old friends during their study abroad, which is often the root cause of loneliness and anxiety in a new land, it is of vital importance for people's welfare to create what could be termed 'surrogate family and friends'. The Chinese cohort seemed to function as such 'surrogate family and friends'; a new supportive network serving to offer support, care and encouragement to each other, particularly when faced with problems, loneliness and anxiety:

Haiyan: ... I had a lot of problems after I came here. My computer broke down. I could not access the Internet, so I could not talk with my family back home. So I went to their rooms to talk with my family using their computers. Later Wenhui and Hualing frequently asked about my computer. That made me feel much better. It would be really inconvenient if one could not use a computer. At that time I felt very sad. ... Now I feel great.

Jing: I feel this is because we are in a group.

(Focus group)

I was fortunate to have come with a group. I could never imagine what benefit it 
would have for me to come on my own. One would feel extremely lonely on their own. I feel it's better to come to study as a group. (Jing, Interview)

One tutor recognised this advantage, too:

[T] he advantages of being a group, with some common backgrounds, common experiences and the ability to be supportive of each other has been a definite advantage. (John, Director of Teaching and Learning, Interview)

As mentioned earlier, in the case of one student (Hongmei) such support within the group turned out to be very significant for her retention on the programme. With careful nurturing by the members of the Chinese cohort, coupled with the strong moral support from her father back home, she had finally been persuaded to stay. Nearly one year on, she was now not only academically successful - judged from her essay grades and the successful completion of her dissertation - but was also confident and independent, a sharp contrast to the quiet and shy girl who seldom spoke in class initially. The strong support from the university, particularly as represented by Dr Zhang, and the ongoing social and cultural support of the LVG were also cited as important contributing factors by Hongmei.

However, being part of a group such as the Chinese cohort was a double-edged sword. Their shared mother tongue, competition among the group, personality clashes and conflicts of values and faith were cited as issues related to group dynamics. The fact that they all had the same mother tongue sometimes prevented them from taking advantage of opportunities to use English, and many of them blamed it for their lack of progress in speaking in English. The following comment was typical:

We expected to improve our speaking greatly. But in fact we live in a group, and we cannot get out of this circle, so we haven't made full use of the chance to improve our speaking in English. The progress in speaking is not that ideal. (Yuhua, Interview)

There was competition among the group, as experienced by some members and as also 
observed by the academics:

I could sense the pressure from within our group. I was quite relaxed at the start, but when I saw others were like crazy, I felt the pressure was on. When I got my first term's results and saw they were OK, I started to feel more relaxed. ... Some started to cry when they got their results... But if you had come on your own, you would only be responsible for yourself. (Xiaoli, Interview)

What I feel is sometimes there is the sense that this is a special group, they have been very carefully chosen, and there are very high expectations on them. They know they are going to return home and they are expected to be somehow very different, somehow very much more special. I know that the pressure is there. ... I can sense it. ... there was an internal pressure to be the best, or one of the best. (John, Director of Teaching and Learning, Interview)

While personality clashes seemed to cause discomfort among some members of the Chinese Cohort initially, real conflicts were sparked by differences around religious beliefs. There was considerable disagreement as to whether it was appropriate for some members to adopt Christianity and whether individuals could really feel free from collective participation in quasi-religious activities (e.g. social gatherings organized by Christians) or religious activities (e.g. Bible Study). The Chinese Cohort was finally divided on the issue of religious beliefs and the group were split into believers, doubters, and observers (see Liu 2011 for more details). Among the Chinese Cohort, and contrary to previous findings (e.g. Liu, 2001; Zeng, 1997), female members seemed to have more difficulty adapting to these far-reaching changes, as indicated by their more emotional response to the situation. Male members also seemed to be divided on the issue, but were not engaged in overt disputes. One member was critical of the limited scope of their social and cultural experiences within the LVG - a predominantly Christian group. She commented on the need to have alternatives to socialization besides the LVG to include a wider social spectrum, although she was aware that these alternative groups were harder to access given their limited time and resources (see Liu, 2011). 
In addition, the presence of a large cohort of a single ethnicity on a programme may have potential impact on the other international student groups. The following comments of John point to this potential issue:

I think the other, our other key area here is to make other students not feel they are not part of that group, because from our point of view, it will be equally the case that one individual, ... let's say from Greece ....might feel ... even more isolated than usual.... We want to make sure those people who are not in a group, or are not in a particular community of international students of the same language, feel part of the larger group; so the other disadvantage would not be for the [Chinese Cohort] but for the other students. (John, Director of Teaching and Learning, Interview)

\section{Incorporation: Student adaptation, retention and academic success}

The strategies of the University, as represented by the School, the efforts of the LVG and those of the members of the Chinese Cohort themselves seemed to have facilitated the transition of the Chinese Cohort, as evidenced in proceeding discussions. More importantly, there also seemed indications of incorporation, a further stage and milestone in van Gennep's conceptual framework.

Despite some initial anxiety over academic work, the Chinese cohort all felt that they had adapted well to the academic culture in the UK. They felt they were able to participate better in seminars than previously, and to gradually cope with the demands of reading and writing. They had changed their attitude to research, developed critical thinking skills and autonomy, and had become more confident in following academic conventions in the UK:

Teaching was often conducted in the form of seminars, probably it's a bit different from how we used to have lectures [in China] and we were more used to absorbing knowledge... later ... I started to participate more. (Hui, Interview)

At the start, when we got the long reading list from the tutor, my classmates and I often fought for the materials to see who could get hold of them first. I was a bit anxious. As for me, I was a slow reader ... I was really not used to it. Later I 
realised that I could get hold of other books [not on the reading list] to read, and tried to get what I wanted from them. I have gradually got used to it. (Haiyan, Interview)

First of all, my attitude towards research [has changed]. ... When I was in China, to put it more bluntly, [there was] a lot of copying of each other's work - now it's even simpler with computers, first 'ctrl $+\mathrm{c}$ ' and then 'ctrl $+\mathrm{v}$ ' ... But here [in the UK] you have to be very accurate with every reference ... In writing, we Chinese tend to go round in circles and not go direct to the point ... the language we use is very flowery but here in the UK, the structure is relatively simple and people use clear simple language. (Wenhui, Interview)

Observations by both academics and support staff seemed to concur too:

My impression was they adjusted well, quickly and they knew what's coming as it were. (John, Director of Teaching and Learning, Interview)

I am thinking in terms of what happens in sessions, ... I think quite often they have appeared to be more autonomous in their thinking, and certainly as time went on over the year, they were less frightened of making critical, and analytical, comments during the sessions. (Colin, Course tutor, Interview)

My perception is they adapted quite well and quite quickly. ...Generally they seemed settled and happy. They seemed to throw themselves into the life here and not only the social life ... but academically, attending the extra modules, because they were interested. They were certainly very hard workers. (Emma, International Programmes Coordinator, Interview)

The assessment results showed that the Chinese Cohort were all successful academically - two final distinctions were awarded, seven merits, and two passes. Overall, then, it was a success story; for Hongmei, the young woman who wanted to return to her father in China as soon as she had arrived in the UK, it was also a case of successful student 
retention.

It would have been a limited experience if the Chinese Cohort had come and gone with only an academic degree. Their stay represented a process of both professional and personal transformation and growth. Culturally, they believed they had gained much insight and most felt they had become more tolerant, despite the apparent division and conflict among the group on the issue of religious conversion. Of particular significance was the commonly reported lack of culture shock among the Chinese Cohort on issues other than the religious beliefs, which could be partly attributed to the wide range of academic, social and cultural support they had received during their transition. One member of the Chinese Cohort, Jing, even commented that for her it was not a matter of transition; she felt it was like putting a fish back in water - she felt she belonged in the UK. Nevertheless, to answer the call of duty and to honour her study abroad agreement with her local education authority, she returned to China with the rest of the Chinese Cohort at the end of her study.

\section{Discussion and conclusion}

The present case study discussed the needs and challenges of a group of Chinese secondary teachers in their transition to UK postgraduate studies in the context of a British-Chinese partnership. The main needs and challenges facing the Chinese students were psychological (e.g. sense of separation and potential isolation from familiar networks), linguistic-academic (the need to acquire competencies associated with the new “discourse community"), and sociocultural (aspiration for a wider social and cultural experience afforded by the new environment). These needs and challenges were discussed within van Gennep's (1960) holistic perspective of separation, transition and incorporation, with particular attention paid to the process of transition in the students' international experience. My own observations suggest that there is a hidden assumption in many higher education institutions - and not only in the UK - that international postgraduate students are somehow able to survive and succeed independently on their programme once they have met the entry criteria set by the institutions and have been taught the standard academic programmes. For example, in my experience it is not 
generally part of a UK Master's programme to offer any detailed systematic training in academic writing. However, as data from the present study show, Chinese students pursuing a relatively short intensive programme such as a Master's in the UK often find themselves struggling initially to cope with the academic demands in their transition.

Tripartite efforts were made by the host institution, the local community and members of the Chinese cohort themselves to address these needs and challenges. The strategies adopted by the host institution included structural and specific measures of support. The former was characterized by a new support structure with dedicated staff and the latter included both targeted support for the students' linguistic-academic skills (e.g. in the form of new modules and support courses) and reactive support in response to their emergent needs. These strategies were complemented with social and cultural support offered by a local volunteer group (LVG) and mutual care and support among members of the Chinese Cohort. Such strategies and efforts helped to ease the students' transition and facilitated their incorporation into new academic and social and cultural communities - a milestone in their personal and professional lives.

It is perhaps important for all parties concerned to recognize the developmental nature of student transition and that the challenges encountered in the process, such as language and study skills, can be addressed with appropriate levels of support. It is also important to recognize that academics and students may differ in their views of what constitutes 'appropriate levels of support', and that academics are often faced with the dilemma of encouraging student independence and offering academic support where it is needed. However, it is important to strike a balance between the two, taking into consideration the needs and aspirations of the students.

In the present context of an international partnership, since the support was targeted for a relatively sizable cohort, it seemed more focused, resource-efficient, and value-added for the partnership and student experience. The support structure and experiences thus developed and the potential cascading effects on future cohorts (e.g. in terms of information, advice, and institutional reputation) is likely to be not only beneficial to the 
students but also sustainable for the partnership institutions.

The analytical framework adopted in the present study highlights the sociological processes of international postgraduate student experience, particularly those of transition during a critical period in the students' lives, which to my knowledge have not been attempted in previous research. The case study strategy enables the foregrounding of the perspectives and meanings that the participants bring to the Chinese students' transitional experience. Despite the limits of case study research, the present study may also contribute to our understanding of issues of student support pertinent to international partnership arrangements. However, as discussed in the methodological section of this article, the issue of boundaries in case studies - as indeed in many other types of studies too - must be borne in mind when attempting to understand the transitional experience of the Chinese students. The contribution of other potential players such as key members in the students' home networks, facilitated by modern communications technologies and the globalised environment, could be relevant and explored in greater depth. Other plausible conceptual frameworks may also be illuminating in the context of international education. For instance, global education and issues of diversity, inclusiveness and internationalised curricula (Thom, 2006; Caruana, 2009; Coverdale-Jones and Rastall, 2009) - current topics of debate - may be lines of further enquiry in the present context too.

\section{References}

Anderson, L., Jacobs, J., Schramm, S. and Splittgerber, F. (2000) 'School transitions: Beginning of the end or a new beginning?'. International Journal of Educational Research 33: 325-339.

Australian Education International (2010) International Student Survey 2010 Overview Report. Available at:

http://aei.gov.au/AEI/PublicationsAndResearch/Publications/2010_International_Stude nt_Report_pdf.pdf (accessed 15 February 2011).

Berkenkotter, C., Huckin, T. N., and Ackerman, J. (1991) 'Social context and socially constructed texts', in C. Bazerman and J. Paradis (eds) Textual Dynamics of the 
Professions: Historical and Contemporary Studies of Writing in Professional

Communities, pp. 191-215. Madison: The University of Wisconsin Press.

Caruana, V. (2009) Internationalising the curriculum: An annotated bibliography

commissioned by Nottingham Trent University. Available at:

http://www.leedsmet.ac.uk/NTU_review_FINAL_150210.pdf (accessed 20 February 2011).

Castells, M. (1997) The Information Age: Economy, Society and Culture, Volume II: The Power of Identity. Malden, Mass.: Blackwell publishers.

Commonwealth of Australia (2007) 2006 International Student Survey. Available at: http://www.aei.gov.au/AEI/PublicationsAndResearch/Publications/ISS_2006_CONS_pdf .pdf (accessed 15 February 2011).

Coverdale-Jones, T. and Rastall, P. (2006) 'The Chinese Learner'. Language, Culture and Curriculum 19: 1-153.

Coverdale-Jones, T. and Rastall, P. (2009) (eds) Internationalising the University: The Chinese Context. Basingstoke: Palgrave Macmillan.

Edwards, V. and An, R. (2006) Meeting the Needs of Chinese Students in UK Higher Education. Available at:

http://www.ncll.org.uk/10_about/50_research/10_research_projects/chinesestudents_ht $\underline{\mathrm{ml}}$ (accessed 1 May 2007).

Edwards, V., An, R. and Li, D. (2007) 'Uneven playing field or falling standards:

Chinese students' competence in English'. Race Ethnicity and Education 10: 387-400.

Emerson, L., Rees, M. T. and MacKay, B. (2005) 'Scaffolding academic integrity: Creating a learning context for teaching referencing skills'. Journal of University Teaching \& Learning Practice 2 (3): 10-24.

Giddens, A. (1991) Modernity and self-identity: Self and society in the late modern age. Cambridge: Polity Press in association with Blackwell Publishing.

Graham, S. (1997) Effective Language Learning. Clevedon: Multilingual Matters.

Gu, Q., Schweisfurth, M. and Day, C. (2010) 'Learning and growing in a "foreign" context: Intercultural experiences of international students'. Compare: A Journal of Comparative and International Education 40: 7-23. 
Guilfoyle, A. (2006) 'Understanding key dimensions of international postgraduate students' transition and learning experiences'. The International Journal of Learning 13(6): 71-78.

Handa, N. and Power, C. (2005) 'Land and discover! A case study investigating the cultural context of plagiarism'. Journal of University Teaching \& Learning Practice 2 (3): 62-84.

Hellstén, M. (2002) 'Students in transition: needs and experiences of international students in Australia'. New times new approaches: Conference proceedings. 16th Australian International Education Conference: Hobart, Tasmania, 30 September - 4 October. Available at: http://www.aiec.idp.com/pdf/Hellsten_p.pdf (accessed 5 January 2011).

Jepson, M., Turner, T. and Calway, B. (2002) 'The transition of international students into post-graduate study: an incremental approach'. Available at: http://www.aare.edu.au/02pap/tur02193.htm (accessed 5 January 2011).

Leask, B. (2006) 'Plagiarism, cultural diversity and metaphor - implications for academic staff development'. Assessment \& Evaluation in Higher Education 31 (2): 183-199.

Leonard, D., Pelletier, C., and Morley, L. (2003) The Experiences of International Students in UK Higher Education: A Review of Unpublished Research. London: UKCOSA. Available at: http://www.ukcosa.org.uk/images/annotbiblio.rtf (accessed 5 June 2007).

Lewins, A. \& Silver, C. (2009) Choosing a CAQDAS Package - A working paper, 6th edition. Available at:

http://eprints.ncrm.ac.uk/791/1/2009ChoosingaCAQDASPackage.pdf (accessed 14 July 2009)

Lewthwaite, M. (1996) 'A study of international students' perspectives on cross-cultural adaptation'. International Journal for the Advancement of Counselling 19: 167-185.

$\mathrm{Li}$, D. (2011) 'Out of the Ivory Tower: The impact of wider social contact on the values, religious beliefs and identities of Chinese postgraduate students in the UK'. Race, Ethnicity and Education. http://www.tandfonline.com/doi/pdf/10.1080/13613324.2011.585339 (Available online: 24 August 2011) 
Liu, S. (2001) Gender differences among Chinese students adapting to the environment of a UK institution (MEd dissertation, University of Bristol), in D. Leonard, C. Pelletier, and L. Morley (2003) The Experiences of International Students in UK Higher Education: A Review of Unpublished Research. London: UKCOSA. Available at: http://www.ukcosa.org.uk/images/annotbiblio.rtf (accessed 5 June 2007).

Lucey, H. and Reay, D. (2000) 'Identities in transition: Anxiety and excitement in the move to secondary school'. Oxford Review of Education 26 (2): 192-205.

Macdonald, R. and Carroll, J. (2006) 'Plagiarism - a complex issue requiring a holistic institutional approach'. Assessment \& Evaluation in Higher Education 31 (2): 233-245.

McGowan, U. (2005) 'Academic integrity: An awareness and development issue for students and staff'. Journal of University Teaching \& Learning Practice 2 (3): 46-57.

McInnis, C. (2001) 'Researching the first year experience: Where to from here?'. Higher Education Research and Development 20 (2): 105-114.

Moss, T., Pittaway, S. and McCarthy (n.d.) The first year experience: Transition and integration into teacher education. Available at: http://www.aare.edu.au/06pap/mos06557.pdf (accessed 5 January 2011).

Ramsay, S., Jones, E. and Barker, M. (2007) 'Relationship between adjustment and support types: Young and mature-aged local and international first year university students'. Higher Education - The International Journal of Higher Education and Educational Planning 54 (2): 247-265.

Roberts, K. A. \& Wilson R. W. (2002) 'ICT and the Research Process: Issues Around the Compatibility of Technology with Qualitative Data Analysis [52 paragraphs]'. Forum Qualitative Sozialforschung / Forum: Qualitative Social Research, 3(2), Art. 23.

Available at:

http://www.qualitative-research.net/index.php/fqs/article/view/862/1873 (accessed 14 July 2009)

Singh, K. and Armstrong, L. (2006) 'International postgraduate student experience: How can we enhance transition management?', in J. Renner, J. Cross, and C. Bell (eds) Engagement and Empowerment: New opportunities for growth in higher education, pp. 460-472. Joondalup WA: Edith Cowan University. 
Stark, S. and Torrance, H. (2005) 'Chapter 3: Case Study', in B. Somekh and C. Lewin (eds) Research Methods in the Social Sciences, pp. 33-40. Los Angeles: Sage.

Swales, J. (2003) 'Is the university a community of practice?', in S. Sarangi, and T. van Leeuwen (eds) Applied Linguistics and Communities of Practice, pp. 203-216. London: Continuum.

The British Council (2008) 'China Market Introduction'. Available at: http://www.britishcouncil.org/eumd-information-background-china.htm (accessed 2 March 2010).

Thom, V. (2006) 'Enhancing the student experience - Global education and integration'.

Paper presented at Going Global 2. The UK's international education conference.

Edinburgh.6-8 December. Available at:

http://www.britishcouncil.org/goingglobal-2__ 5e__ viv thom.pdf (accessed 5 January 2011).

Tinto, V. (1988) 'Stages of student departure: Reflections on the longitudinal character of student leaving'. Journal of Higher Education 59(4): 438-455.

Trotter, E. and Roberts, C. (2006) 'Enhancing the early student experience'. Higher Education Research \& Development 25(4): 371-386.

UKCOSA (2004) Broadening Our Horizons: International Students in UK Universities and Colleges. London: UKCOSA. Available at: http://www.ukcosa.org.uk/survey/index.htm (accessed 2 February 2005).

UKCOSA (2007) Benchmarking the provision of services for international students in higher education institutions. London: UKCOSA. Available at: http://www.ukcisa.org.uk/about/material_media/research_reports.php (accessed 10 November 2010).

Van Gennep, A. (1960) The Rites of Passage. London: Routledge.

Weitzman, E. A. and M. B. Miles (1994) Computer Programs for Qualitative Data Analysis. London, Sage Publications.

Yin, R. (2003a) Case Study Research: Design and Methods (3 ${ }^{\text {rd }}$ ed.). Thousand Oaks, CA: Sage.

Yin, R. (2003b) Applications of Case Study Research (2 $\left.{ }^{\text {nd }} e d.\right)$. Thousand Oaks, CA: Sage. 
Zeng, J. (1996) 'When East meets West: Mainland Chinese students and scholars in UK Higher Education institutions'. Journal of International Education 9: 9-15.

\section{Biographical note}

Daguo $\mathrm{Li}$ is a lecturer at the National Centre for Language and Literacy, the University of Reading, UK. His research interests include international education, professional development of second language teachers, and motivation and strategies in second language learning. 